\title{
THE TREATMENT OF LEPROSY WITH SULPHETRONE.
}

\section{T. F. DAVEY.}

Sulphetrone, (tetrasodiumphenylpropylamino-diphenyl sulphone tetrasulphonate), a new sulphone drug, has been used experimentally in the treatment of leprosy at Uzuakoli Settlement for Io months, and although 37 patients are now undergoing therapy with it, this report is confined to the $\mathrm{I} 7$ cases who have received the drug for more than 5 months. . 
When the clinical trial of sulphetrone was contemplated, trials with diasone had already been in progress for 12 months, and in view of the progress of patients receiving diasone, it was felt desirable to provide rigorous conditions for testing the new drug by selecting the most unpromising cases that were available. The I7 cases concerned were all lepromatous patients of varying degrees of severity, some of them extremely heavily infected. They were classified as follows

$\begin{array}{llll}\text { Advanced nodular or diffuse leproma } & \ldots & \ldots & 4\end{array}$

(Cases $4,5,7,15$ )

Moderately advanced ditto (Cases I, 8, I0, II, I2, I6, I7)

Early or mild ditto macules)

(some also exhibiting macules)

(Cases 2, 6, 13, 14)

Macular lepromatous cases

(without nodules or obvious diffuse infiltration)

(Cases 3, 9)

All these patients had received treatment with hydnocarpus oil in adequate dosage for varying periods, three of them for more than Io years. In 7 cases the disease was advancing rapidly, with a very bad prognosis. In the remainder the infection had clinically been more or less stationary for some time. These circumstances provide the only form of control possible in a trial of this nature. The two macular cases were included for the sake of interest. All cases were adults, but after experience with the drug the experiment has recently been enlarged by the addition of 20 children to the series of patients.

\section{Dosage.}

The drug is supplied in tablets of $0.5 \mathrm{gm}$, and therapy commenced with one tablet each week according to tolerance, up to a daily dose of 3 gms, given on six days of the week. When this standard daily dose was reached, without toxic signs, the drug was given in courses of six weeks at this dosage, followed by two weeks rest. Although there was some individual variation, this dosage proved suitable and has been maintained. During the rest periods and during parts of the course, patients also received ferrous sulphate, gr. 3 b.d.

\section{TOXIC SIGNS.}

Observations were made at suitable intervals throughout the course of treatment of patients' weight, daily temperature range, urine, hæmoglobin, E.S.R., and red and white blood cell counts. A hypochromic anæria developed in 15 out of the 17 cases, the 
decline in red cell count varying between 100,000 and 800,000, with an average fall of 450,000. The lowest figures in individual patients were reached between the second and the sixth month of therapy, after which the count tended to rise again, and in 9 cases it is now higher than at the start of the experiment. In all patients hæmoglobin percentage has remained in the neighbourhood of $60 \%$. The white cell count has shown no significant variation. There has been no evidence whatever of kidney damage. Patients have not complained of nausea, vomiting or disturbances of vision. Headache has been experienced by three patients, but in only one of these could the suphetrone possibly be implicated. Symptoms of lepra reaction have appeared in three patients, in all cases mild, and further reference will be made to these. The drug has proved to be relatively atoxic in the dosage employed. Blood concentration es.

\section{Clinical PROGRESS.}

In general condition every patient has improved. The weight has increased in 6 , decreased in 7 .

Individual notes on the $\mathrm{I} 7$ patients are appended.

\section{Comments.}

Of the I7 cases reported on, I3 have received sulphetrone for Io months, I for 9 months, 2 for 6 months, and one for $5 \frac{1}{2}$ months. They have received no other anti-leprosy treatment during this time. No patient has become worse. In two there is little change, but all the rest showed real and notable improvement, in 7 cases the improvement being very marked indeed, nodules becoming absorbed and infiltration diminishing. The improvement was particularly striking in the advanced and degenerating cases, in all of whom the outlook of the case has been entirely transformed. In most cases improvement was apparent within three months of the first dose. The progress of the series is summarised a follows.

Great improvement

7 cases

(Nos. 4, 5, 7, I3, I5, I6, I7)

Moderate improvement $\ldots . \ldots . \ldots$

(Nos. I, 2, 6, 8, 9, II, I2, I4)

Slight improvement

8 cases

\begin{tabular}{lllrrrr}
\multicolumn{7}{c}{$($ Nos. 3, ro) } \\
Stationary & $\ldots$ & $\ldots$ & $\ldots$ & $\ldots$ & $\ldots$ & Nil \\
Worse & $\ldots$ & $\ldots$ & $\ldots$ & $\ldots$ & $\ldots$ & Nil
\end{tabular}

The bacteriological findings have not followed the clinical improvement. This is not surprising, and has been discussed by Muir in relation to diasone therapy (I). Nevertheless, two cases 
have become bacteriologically negative, and in 9 others, bacilli, formerly exceedingly numerous, have diminished in recent tests, promising findings in view of the relatively short period of trial, and the type of case concerned. In this respect sulphetrone compares favourably with diasone.

Although most cases have improved steadily without interruption and without evidence of lepra reaction, a few showed heightened sensitivity to the drug and care with dosage was necessary. Case No. I is of particular interest. Here a lepromatous condition of many years duration, already extensive and degenerating, began to improve -steadily during sulphetrone therapy, until without warning and without constitutional symptoms, five months after the first dose, a papular exanthem appeared, the lesions of which proved on biopsy to be atypically tuberculoid in nature, while the lepromin reaction changed from negative to strongly positive. These lesions have tended slowly to subside and, although bacilli remain numerous in them, degenerating forms are frequent. The change from the lepromatous to the tuberculoid phase is an extremely rare phenomenon, and was probably influenced by the sulphetrone in this case. After some weeks rest sulphetrone was resumed in this case on a standard dose of $2 \mathrm{gm}$ daily. The further progress of this remarkable case will be of interest.

Another case calling for comment is case No. 6. After four months therapy this patient began to exhibit a succession of vesiculo-pustular lesions on the face, which discharged a bead of pus containing large numbers of degenerating bacilli. The patient at this time began to be very sensitive to sulphetrone, doses in excess of I gm stimulating more of these lesions. An increase above this dose in the month of October resulted in an acute reaction, with œdema of the face and a large number of large pustular lesions. On the neck, limbs and trunk, wheals and flat pink macular areas appeared. The drug was'discontinued and these rapidly disappeared, and three weeks later the patient was very fit. There has been marked clinical improvement in this patient, but close medical supervision is necessary. It is of interest to note that a precisely similar condition has arisen in a child who recently commenced sulphetrone therapy, numerous vesicular lesions appearing within one month of starting the drug.

In case No: Io also, a macular eruption has appeared, faint and poorly defined, becoming marked after 7 months of sulphetrone therapy. There were no constitutional symptoms, but the macules have persisted and the bacteriological test has become negative. There appears to be a tendency for the drug to stimulate a mild 
lepra reaction with the appearance of macules. A similar tendency has been noted with diasone. It is of interest that in II of the I7 cases, the lepromin test has changed from negative to positive. This allergising effect in some individuals calls for careful supervision of the drug.

Case I. Ref. No. 565. Male. Age 35. Moderately advanced lepromatous case, diffuse thickening plus nodulation. Rapidly legenerating. Has had hydnocarpus oil treatment for ten years Commenced sulphetrone treatment 20/1/47.

Report. (26/5/47). I Jramatic improvement. Lepromatous ulcers on legs have healed, nodules are becoming absorbed, and infiltration of face is noticeably less. Bacteriological findings show little change as yet. Drug has produced no toxic signs. Red cell count has actually improved.

Report. (9/7/47). The patient has suddenly produced an extensive eruption of papules which have united in some areas to form macules inclistinguishable from tuberculoid lesions in appearance. Bacteriologically strongly positive with globi, but lepromin formerly negative is now 3 plus.

Report. (I//I/47). Lepromin continues + ve. The eruption mentioned in previous report is still present and the patient continues in a borderline state between leproma and tuberculoid. Biopsy shows a heavy infiltration of epitheloid cells in what is otherwise a lepromatous section, with a tendency to giant cell formation, The eruption has tended to flatten. It is still bacteriologically + ve. The lepromatous infiltration of face and ears is rapidly resolving with diminution of bacilli and the general condition of this remarkable case is good.

Case 2. Ref. No 4939. Male. Age 35. Early nodular lepromatous cases with macules and nodulation of ears. Has had hydnocarpus oil treatment for $I_{2}^{\frac{1}{2}}$ years with only slight improvement. Commenced sulphetrone treatment $20 / 1 / 47$.

Report. $(26 / 5 / 47)$. Improved. Macules have faded, nodulation persists. Bacteriological findings still 4 plus. Patient feels very fit. No toxic manifestations.

Report. (I $4 / \mathrm{I} / 47)$. Continued improvement: Patient is very fit. Skin is still strongly + ve.

Case 3. Ref No. 4921. Male, Age 40. Borderline tuberculoid case, exhibiting innumerable macules, bacteriologically positive, little unaffected skin remaining. Disease stationary. 8 months treat. ment hydnocarpus oil. Commenced sulphetrone treatment on $20 / \mathrm{I} / 47$.

Report. (15/5/47). Nuch improved Now bacteriologically negative. No toxic manifestations

Report. $(1+1 / 1 / 47)$. Patient is very fit but no change from last report.

Case 4. Ref. No. 3024. Female, Age I9. Advanced nodular leprosy with sunk nose and florid nodulation of face and ears, small nodules on all parts of the body. Has had hydnocarpus oil treatment for 13 years. Commenced sulphetrone treatment on $20 / 1 / 47$.

Report. (I5/5/47). Stationary, but patient feels fit and prefers sulphetrone to hydnocarpus. oil. R.B.C's have fallen by 200,000 . Report. $(1+11 /+7)$. Since May this patient has shown dramatic improvement as is brought out by photographs. Bacilli are becoming less in numbers in most recent tests.

Case 5. Ref. No. 20ri. Female. Aged 40. Moderately advanced nodular leprosy degenerating. Has had hynocarpus oil treatment for I4 years. Commenced sulphetrone $20 / 1 / 47$. 
Report. (15/5/47). I)ramatic improvement. Nodules resolving. Patient formerly a misery to herself and other people is now happy. R.B.C's have fallen by 400,000 . Bacteriological findings still 4 plus.

Report. ( $14 / 1 \mathrm{I} / 47)$. Improvement is maintained and bacilli are becoming fewer in smears from the skin.

Case 6. Ref No. 721. Male. Age 30. Extensive though early lepromatous infection with nodulation. I year's treatment with hydnocarpus oil, and showing improvement. Commenced sulphetrone on $20 / 1 / 47$.

Report. $(15 / 5 / 47)$. Dramatic improvement. Noclules resolving' very rapidly. J3acteriological findings still + plus. R:13.C's have fallen by 800,000 . June 1947. This patient for the last three weeks has been in a state of mild lepra reaction, with a succession of small pustules appearing on the face, discharging a bead of pus containing many lepra bacilli, and healing almost without scars. Dosage of sulphetrone has been cut out for a week, then resumed, then cut out for a week. Improvement is most marked.

Report. ( $\left.\mathrm{I}_{4} / \mathrm{II}_{\mathrm{H}}+7\right)$. The mild leproma reaction reported in June settled down leaving the patient considerably improved, but only sensitive to sulphetrone small closes (1 gm.) leading to recrudescence of pustulation on the face. He has continued intermittently on this dose and, when increased in Octolser, another reaction occurred more marked than in June but having he same characteristics. This has now settled down. Bacteriological test remains strongly + ve in skin but bacilli are not so numerous in the ear.

Case 7. Ref. No. 8rg. Male. Age 35. Extremely virulent lepromatous infection, with advanced nodulation and infiltration and rapid degeneration. Commenced sulphetrone on $20 / 1 / 47$ after only two months treatment of hynocarpus oil.

Report. (I5/5/47). Dramatic improvement. Erythema much less, and videspread alssorption of nodules and infiltration. Bacteriology still 4 plus. R.B.C's have fallen by 200,000 .

Report. (I 4/I I/47). The dramatic improvement reported in May still continues and a hopeless case is completely transformed with widespread absorption of leproma. Marked diminution of bacilli in ears.

Case 8. Ref No. 489 . Male. Age 30. Longstanding moderately advanced diffuse lepromatous case. Hydnocarpus oil treatment for 4 years with conditions stationary. Soluthiazole course Oct. $/ 46-$ Jan./47 without visible effect. Commenced sulphetrone 3/2/47.

Report. (15/5/47). Clinically little change. Bacteriological test shows diminution of bacilli from a plus to plus' scanty. R.B.C's have fallen by too,000

Report. $(1+1 / 1 / 47)$. The patient is very fit and in recent tests bacilli are found to be fewer than formerly.

Case 9. Ref. No. 701. Male. Age 40. Lepromatous macular case with innumerable lepromatous macules, improving after 6 years' treat. ment with hydnocarpus oil. Soluthiazole course Oct./46-Jan./47. Commenced sulphetrone $3 / 2 / 47$.

Report. (I $5 / 5 / 47$ ). Improved, macules fading and have become bacteriologically negative. No toxic symptoms.

Report. (I4/II/47). The patient is very fit and in recent tests bacilli are found to be fewer than formerly:

Case Io. Ref. No. 4604 . Male. Age 33. Moderately advanced lepromatous case with erythematous lepromatous macules and diffuse infiltration of the face. + years' treatment with hydnocarpus oi] with some improvement. Commenced sulphetrone $3 / 2 / 47$.

Report. (15/5/47). Marked improvement, Racteriologically negative. No toxic effects. 
Report. (14/II/47). In August.an eruption of faint papulate macules appeared most marked on the buttocks and poorly definecl. Bacteriological test is now negative.

Case I1. Ref No. 47Io. Male. Age 3o. Moderately advanced lepromatous case with infiltration and highly erythematous macules. 3 years' hydnocarpus oil treatment without effect. Soluthiazole course $3 / 2 / 47$.

Report. (15/5/47). Marked improvement. Erythema disappeared and no toxic signs.

Report. (I4/I I/47). Improvement maintained. Macules invisibl: No change in bacteriology.

Case I2. Ref. No. 4667. Male. Age 30. Moderately advanced nodular leproma. No improvemesit after + years' treatment with hydnocarpus oil. Sulphetrone started $3 / 2 / 47$.

Report. (15/5/47). $\Lambda$ crop of macules of lepromatous infiltration has diminished. No change in bacteriology. No toxic signs.

Report. ( $14 / \mathrm{II} / 47)$. The macules mentioned in the first report are graclually becoming more pronounced, and bacilli are not as numerous in skin smears.

Case 13. No. 49I4. Male. Aged 25. Early lepromatous case with nodular ears ancl numerous erythematous macules. Commenced sulphetrone therapy $10 / 2 / 47$.

Report. (15/5/47). Improved. Macules are flattening and muscular power in hands improved. No change in lacteriology. No toxic signs.

Report. (14/11/47). Remarkalsle improvement occurred in this case. Nodules of cirs have disappeared and general condition is excellent. There is diminution in numbers of bacilli in smears.

Case I4. Ref. No. 236. Male. Age 45. $\Lambda$ mild lepromatous case who has remained stationary for a long time. Commenced sulphetrone therapy $3 / 3 / 47$.

Report. (I $4 / \mathrm{II} / 47)$. Patient is very fit. Erythema has disappeared from lesions. l3acteriology remains mildly + ve.

Case 15. Ref No. 4943. Male. Age 32. A rapid degenerating florid nodular case becoming advanced and with hopeless prognosis. Commenced sulphetrone therapy $26 / 5 / 47$.

Report. (14/II/47). Remarkal)le improvement. Nodulation everywhere diminishing. Improvement marked in eyes.

Case r6. Ref. No. 805. Male. Age 30. $\Lambda$ widespread nodular case of two years' history. Ex-serviceman. Sulphetrone therapy commenced $26 / 5 / 47$.

Report. (I +/II/47). Very great improvement with widespreaci diminution of nodulation. Lepromin has become positive.

Case 17. Ref. No 493. Male. Age 29. Degenerating nodular case. A nurse. Commenced sulphetrone therapy 3/7/47.

Report. (14/1 I/47). Much improved. Nodulation disappearing rapidly. Bacilli declining in numbers in skin smears.

Acknowledgment is hereby made to the Director of Medical Services, Nigeria for permission to publish this article.

\section{REFERENCES.}

(1) Murr, E. 1947 British Medicul Journal, 7.6.47, p. 799.

- (2) Wharton, L. H. Internat. Jour. Lep., Vol. XV, 1947, p. 231. 